\title{
Research on Evaluation System of Mental Health Education Work for Postgraduate Students
}

\author{
Hongxia Li \\ School of Education and Sports, Bohai University, Jinzhou, 121013, China \\ bdlhx@126.com
}

Keywords: postgraduate students; mental health education; evaluation system

\begin{abstract}
Postgraduate students as a highly educated training of highly educated personnel, mental health status has been widely concerned about the community to strengthen the mental health education of postgraduate students, has become a new era of postgraduate education which cannot be ignored an important issue. Mental health education evaluation is an important means to test the work of mental health, evaluation system is to carry out the evaluation of the basic work. Based on the postgraduate's mental health education system, this paper constructs the evaluation system of postgraduate's mental health education. The evaluation system consists of six first-level indicators, "organization and management, educational input, team building, educational process, educational approach and educational effect". Each level index also contains five secondary indicators. Individual indicators can be adjusted to improve the scientific nature of the evaluation results when face with practical applications.
\end{abstract}

\section{Introduction}

Mental health points to a certain state of mind, education is a social activity of people. Mental health education is to improve and maintain the level of mental health, to enhance people's psychological quality for the purpose of educational activities. Specifically, the mental health education is the educator from the physical and mental development of the characteristics of education, the use of psychology and pedagogy and other related disciplines theory and technology, through a variety of ways and means, purposeful and planned to the educated psychological education to guide, to ease the psychological conflict, adjust the psychological function, enhance mental health, the development of psychological potential, and promote the education of all-round development of educational activities. School is the place of education, mental health education is an important part of school education, mental health education as a kind of educational activities, highlighting the school mental health education and social psychological activities to help the different, highlighting the professional mental health The difference between the institutions, highlighting the school's mental health education, initiative and comprehensiveness, and thus with the requirements of the party and the government, and all students on the mental health education expectations coincide.

The postgraduate's mental health education is based on the characteristics of postgraduate students. The educators use the relevant knowledge theory and professional skills through psychological counseling, mental health education courses, mental health education activities, discipline infiltration and optimization of environment according to the characteristics and laws of postgraduates' physical and mental development methods and ways to help postgraduate students to properly solve the psychological problems in the process of growth, improve the personality development, and promote the comprehensive development of postgraduate education activities. As the highest level of school education, postgraduate education is not only related to the overall level of the school to enhance, but also to cultivate high-end talent, building a high level of discipline, support the country's comprehensive development of the important link. With the continuous expansion of the scale of postgraduate education, as well as increasing social competition, postgraduate students face the learning, life and career and other aspects of the pressure is also 
growing, mental health problems continue to directly affect and restrict the postgraduate students actively engaged in scientific research of interest, as well as the ability to play independently. To strengthen the mental health education of postgraduates has become an important subject that cannot be neglected in postgraduate education in the new period.

Evaluation is a kind of value judgment activity, is the object to meet the needs of the subject to judge. According to the educational values or educational goals, the educational evaluation will provide the basis for improving the quality of education and the decision-making of education through the systematic scientific information collection and collection of information materials and analysis, and the value judgment of educational activities, educational process and educational results. Mental health education evaluation refers to the activities and procedures of judging the situation of mental health education through systematic collection of relevant information, follow the principle of reasonable evaluation, and using special evaluation methods and techniques according to certain evaluation index system and standard. This paper is based on the systematic analysis method, the research on the evaluation system of postgraduate's mental health education, which is conducive to the teaching of education and teaching, which is conducive to the implementation of quality education, which is beneficial to the optimization of the educators themselves. It is beneficial to the postgraduate student's mental health, which is beneficial to the comprehensive development of postgraduate students, which is beneficial to the growth of postgraduate students. It is beneficial to the harmony of the campus, which is beneficial to the stability of the community and beneficial to the social civilization.

\section{Mental Health Education System for Postgraduate Students}

The mental health education system of postgraduate students is composed of five parts: university, mental health education center, college, tutor and communication circle, as shown in Fig. 1.

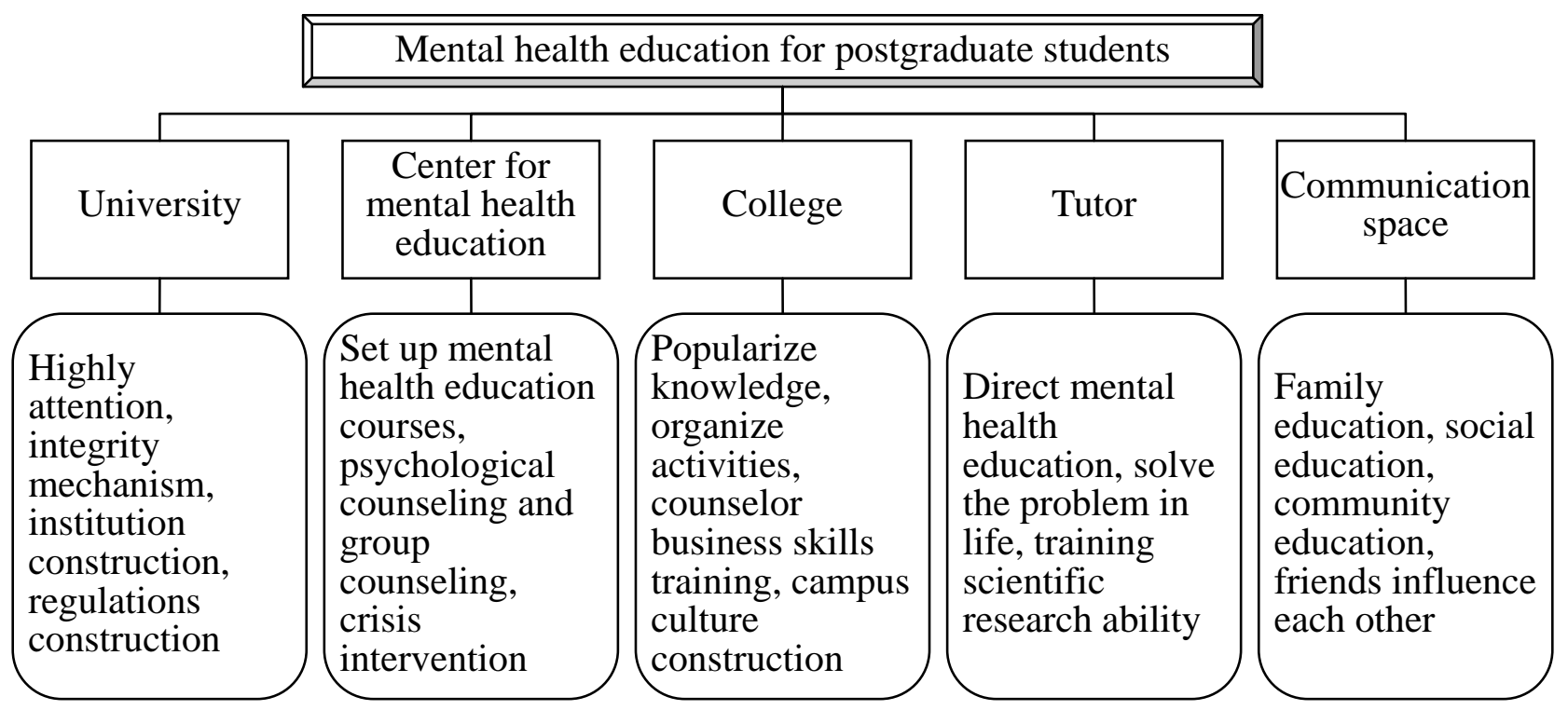

Fig. 1. Mental health education system for postgraduate students

University, is the leader of postgraduate mental health education. Postgraduate mental health education work smoothly, cannot do without the school leaders attach great importance and support. The school should put the mental health education and counseling work of postgraduate students into the ideological and political education agenda, formulate policies and systems, give support in human, material and financial resources, and fully mobilize the enthusiasm of all parties. Strengthen the construction of hardware, strengthen the software construction, strengthen the network mental health education construction, improve the mental health education work knowledge and skills, establish the evaluation mechanism, ensure the orderly conduct of postgraduate mental health education. 
Mental health education center, is the provider of the postgraduate student mental health education professional knowledge. Popularize mental health knowledge, help postgraduate students to establish a good mental health awareness. Identify psychological abnormalities, understand the common mental health problems. Through individual advice, group counseling, telephone counseling and network consulting and other forms, for postgraduate students to provide timely, effective and high-quality mental health guidance services. Strengthen the operation mechanism of individual consultation, implement the appointment and emergency merger system, emergency cases in accordance with the psychological crisis intervention process, and gradually establish and improve the psychological barrier network of postgraduate students.

College, is the implementation of mental health education for postgraduates. Combined with the actual needs of postgraduate students in the curriculum to properly increase the mental health courses, improve the mental health of graduate students. To strengthen the construction of counselors, the college should set up postgraduate full-time counselors, counselors to carry out business skills training, to further improve the work of postgraduate counselors responsibilities, and the corresponding assessment and evaluation and reward and punishment mechanism. Popularize the mental health knowledge, organize a rich and colorful campus cultural life, can effectively adjust and alleviate the emotions and stress of postgraduate students, buffer psychological problems, promote the formation of health psychology.

Tutor, is the guide of postgraduate mental health education. Tutor as a postgraduate student to study the research leader, must strengthen the study methods of postgraduate students, learning motivation and learning pressure and other aspects of counseling. The study of life and economic aspects of care, create a harmonious relationship between teachers and students. In the process of training, according to the postgraduate study and scientific research situation, respectively, put forward different requirements, regular conversation with the postgraduate students to carry out psychological counseling and education. At the same time, attention to the postgraduate career planning and development of the guidance, establish a correct outlook on life and values.

Communication space, is the impact of postgraduate mental health education. It mainly compose of four factors: first, family education, parents are the first teacher of the child, but also a lifelong teacher. Parents 'psychological quality and educational level play a key role in the cultivation and formation of children's psychological quality, and must pay attention to family mental health education. Second, social education, society to reduce the psychological burden of postgraduate students to contribute to the healthy growth of postgraduate students to create a relaxed psychological environment. Third, community education, that is, by the service of social groups for mental health education. Fourth, the mutual influence between friends.

\section{Composition on Evaluation System of Mental Health Education Work for Postgraduate students}

The evaluation system refers to the organic whole with the internal structure composed of the characteristics of the evaluation object and the interrelations of the various indexes. According to the principles of purpose, comprehensiveness, feasibility, dynamic, scientific and systematic, with reference to the relevant literature, this paper constructs the evaluation system of postgraduate's mental health education, which consists of six first-level indicators and 30 secondary indicators, as shown in Fig. 2.

Organizational management, the five secondary indicators are briefly described as follows: (1) university physical education, mental health education as an important part of daily education, rose to the same degree of scientific knowledge education and ideological and political education; (2) perfect rules and regulations, rules and regulations are the ideological and political education work carried out smoothly, but also scientific, complete and practical management of the embodiment; 3 ) mental health center, for the postgraduate students to carry out mental health education and counseling work, build mental health education network service platform, carry out various forms of mental health education and propaganda activities, expand mental health education work way; 4) educational services configuration, colleges and universities should set up a special mental health 
education institutions, complete teaching and extracurricular counseling work; (5) educational staffing configuration, equipped with a dedicated postgraduate student mental health education staff, for the characteristics of postgraduate students mental health counseling.

\begin{tabular}{|c|c|}
\hline \multicolumn{2}{|c|}{ Evaluation index system of mental health education work for postgraduate } \\
\hline Drganizational $n$ & Educational investment \\
\hline University special attention & Special funding investment \\
\hline Perfect rules and regulations & Mental counseling room construction \\
\hline Mental health center & Postgraduate mental health files \\
\hline Educational services configuration & Mental health assessment software \\
\hline Educational staffing configuration & Books and audio-visual products \\
\hline Team construction & Educational process \\
\hline Full-time teacher & Systematic education plan \\
\hline Part-time teacher & Scientificalness education procedure \\
\hline External experts & Creative education method \\
\hline Postgraduate tutor & Collection and management of information \\
\hline Postgraduate counselor & Analysis and application of information \\
\hline Educational approach & Educational effect \\
\hline Mental health curriculum & Mental health assessment \\
\hline Individual mental health coaching & Smooth graduation rate \\
\hline Lecture on mental health & Academic performance improvement \\
\hline Construction of campus culture & Teacher education ability \\
\hline Parental assistance education & Teacher research achievement \\
\hline
\end{tabular}

Fig. 2. Composition on evaluation system of mental health education work for Dostgraduate students

Educational investment, five secondary indicators are briefly described as follows: (1) special financing investment, is to carry out the basic guarantee of mental health education for the purchase of equipment, scientific research, teacher training, organizational activities and performance incentives, etc., through a variety of channels to raise funds; (2) mental counseling room construction, the college to choose a quiet location, the establishment of a dedicated postgraduate counseling room, equipped with advanced hardware facilities to create a comfortable and warm environment; (3) postgraduate mental health files, which will be used as the basis of psychological counseling and counseling in the form of archives, such as personal profile, family situation, learning performance, personality traits, psychological status, learning motivation and moral character of postgraduate students; (4) mental health assessment software, the purchase or development of mental health assessment software, support for mental health assessment, postgraduate students can also own evaluation; (5) books, magazines and audio-visual products, is the necessary material for mental health, for postgraduate students or teachers to learn to use.

Team construction, the effectiveness of mental health education work depends largely on the quality of the people who carry out education. Although most of the mental health teachers are 
more familiar with the work of postgraduate students, good professional ethics, but teachers engaged in mental health education, the general lack of necessary knowledge and practical ability. Mental health education is a very professional work, the teacher's professional quality and overall quality requirements are high. It is necessary to strengthen the professional ability cultivation of college teachers' mental health from various aspects, to meet the development needs of postgraduate students, to guide all aspects of life, study, thought and so on, to solve all the psychological problems of postgraduate students and to promote the comprehensive development of postgraduate students. In view of the actual needs of the current college student's mental health education, the establishment of a variety of roles composed of teachers, include: (1) Full-time teacher; (2) Part-time teacher; (3) External experts; (4) Postgraduate tutor; (5) Postgraduate counselor.

Educational process, the five secondary indicators are briefly described as follows: (1) systematic education plan, mental health education should be systematically and coherently, handle the order of educational activities and the logical order of subject knowledge, and the order of knowledge and ability development of postgraduate students to ensure the systematic knowledge of postgraduate students; (2) scientificalness education procedure, with the passage of time and the deepening of research, people gradually realize the complexity and diversity of the educational process, not only the process of cognition, but also the process of psychological activity and the process of socialization; (3) creative education method, not only to expand the postgraduate students knowledge, but also to improve postgraduate students emotions, change attitudes, to develop the necessary social skills; (4) collection and management of information, collection and collation of relevant information, as a basis for scientific research and psychological health counseling; (5) analysis and application of information, through information analysis, found that mental health education work problems, and take targeted improvement measures.

Educational approach, the way to carry out mental health education can be varied, schools should be based on their own actual situation, the flexibility to choose and use, pay attention to play a combination of various ways to enhance the effect of mental health education. This paper designs five ways, namely, five secondary indicators, briefly described as follows: (1) mental health curriculum, through classroom teaching to achieve mental health education, careful not to psychological counseling courses into a simple knowledge transfer course; (2) individual mental health coaching, for the psychological problems of postgraduate students, the implementation of targeted counseling; (3) lecture on mental health, involving a wide range, rich in content, not only for postgraduate students have a better understanding of mental health, but also on the mental health of graduate students play a positive role; (4) construction of campus culture, play the psychological function of campus culture environment, cultivate the healthy personality of postgraduate students, adjust the psychological state of postgraduate students, and promote the effective internalization of knowledge of mental health education; (5) parental assistance education, as a supplement to mental health education, sometimes also play a very important role.

Educational effect, continuously improving the educational effect is one of the goals of mental health education. The evaluation of the effect should be carried out from various aspects. Five secondary indicators are selected in this paper, which are briefly described as follows: (1) mental health assessment, the evaluation results are the most important indicators of educational evaluation, to make a longitudinal comparison of the evaluation results, to understand the mental health of postgraduate students at different times; (2) smooth graduation rate, which is the most easy to obtain the index of data, at the same time to analyze the mental health of postgraduate students did not successfully postgraduate; (3) academic performance improvement, strengthen mental health education, improve the level of mental health, to improve postgraduate students' achievements and comprehensive quality has positive significance; (4) teacher education ability, including the level of education of mental health education and other scientific knowledge education level; (5) teacher research achievement, mainly in the field of mental health research, including the implementation of the program adopted, as well as papers, patents, works and research topics. 


\section{Conclusion}

Constantly promote the mental health education of postgraduate students, the key is to a comprehensive and scientific evaluation of mental health education. Through the evaluation, establish the psychological and psychological basis of postgraduate's mental health education, improve the concept and mode of mental health education for postgraduate students, enhance the professionalization and scientificization of postgraduate's mental health education and to improve the effectiveness of postgraduate's mental health education. The evaluation system constructed in this paper lays the foundation for the evaluation of the mental health education of postgraduates, and can adjust the individual indexes in order to improve the scientific nature of the evaluation results.

\section{Acknowledgement}

This work is supported by Postgraduate teaching reform project of Bohai university in 2016: Research on evaluation system of mental health education work for postgraduate students (071502221); Social science fund project of Liaoning province: Research on methods and paths of mental health education for postgraduate students (L16BZZ001).

\section{References}

[1] M. Y. Zhu, "Investigation and Analysis of Mental Health Education of Postgraduates," Heilongjiang Researches on Higher Education, vol. 36, no. 3, pp. 117-121, 2017.

[2] Y. P. Gong, "Effect of college students mental health education evaluation," Technology and Market, vol. 22, no. 6, pp. 355-356, 2015.

[3] H. B. Tang, J. J. Xu, Y. P. Wang, "Exploring the Psychological Health Education System for College Postgraduates," Higher Education Forum, vol. 15, no. 4, pp. 109-111, 2009.

[4] G. R. Jiang, Z. H. Ren, "Construction of evaluation index of school mental health education based on CIPP model," Educational Research and Experiment, vol. 29, no. 4, pp. 82-87, 2011.

[5] M. Li, "Study of College Graduates Psychological Health Educating Model Construction," Master's Degree of University of Electronic Science and Technology, 2013.

[6] Y. J. Mi, Y. P. Huang, "Status quo of evaluation of psychological health education in Universities," School party building and Ideological Education, vol. 32, no. 4, pp. 71-72, 2014. 